\title{
Restoration of Manager's Work Identity in Manufacturing Organisations: the Role of Service Operations Design
}

\author{
Ayham A.M. Jaaron \\ Department of Management and Entrepreneurship, Leicester Castle Business School, Hugh \\ Aston, De Montfort University, Leicester, LE2 7BY, UK
}

\begin{abstract}
Strategies used for regulating and improving service departments' managers' (SDMs) valued identity at work through viable and sustainable models of operation are relatively missing. This is particularly true when one considers the paucity of previous studies that have explored the linkages of service operations designs and the construct of SDMs' work identity. This paper, using the lens of identity theory, explores the impact of creating an appropriate service operations design, using systems thinking principles, on the restoration of SDMs' work identity and behaviour. Using multiple-case study approach in three organisations' service departments in the UK, the results demonstrate that the systems thinking for service operations design is an enabler for promoting dramatic changes to the role of SDMs in the workplace. These dramatic changes are resembled by the creation of a transformational management style, changing the role of SDMs from employees' monitors to supporters, and adoption of new discursive practices that are embracing more peoplecantered perspective. While the paper introduces an interesting theorisation of manager's identity with systems thinking methodology, it also contributes, for the first time, a discussion of manager's identity theory to the service system design literature in a highly demanding business environment.
\end{abstract}

Keywords: work identity; service operations design; service departments; managers' identity; systems thinking; personnel development; human resources.

\section{Introduction}

In today's era of globalisation and increased competition, manufacturing organisations have recognised that support services superiority is a significant guarantor through which competitive advantage can be achieved (Al-Mutairi, Burns, and Backhouse 2005; Phusavat 2008; Jaaron and Backhouse 2011). A central tenet in this view is the increasing likelihood of anxiety, stress, and job dissatisfaction of manufacturing support services managers (MSSMs) with increasing job responsibilities and workloads; magnified by ever changing customer demands and requirements and a top management constant pressure to perform better and better (Udo, Guimaraes, and Igbaria 1997; Tripathy 2002; Gadinger et al. 2010). This is due to the fact that MSSMs are under pressure to demonstrate good results (Rai and Kumar 2012). 
However, this role stress and anxiety of MSSMs takes many forms, such as meeting deadlines, achieving workplace targets, strict customer contact protocol enforcement, employees' scheduling, strict budgets, coordination with other departments, and ensuring customer demands fulfilment (Srivastava 2011), coupled with other demands arising out of his social obligations such as family and friends (Tripathy 2002). In recent years, management development practices for MSSMs, among other managers, have been limited to only offering programmes and courses solely covering functional aspects of the role (Fish 1985; Warhurst 2011; Warhurst 2012), neglecting the development of their self-esteem in the face of increasing role pressure and management stress. This perspective, whilst emphasizing the role of cognitive learning for MSSMs, suggests that MSSMs lack supporting operational structures necessary to apply what they have learnt. Consequently, most efforts overlook the need for MSSMs to learning how they can fit their role for an eventual realisation of their self-potential (Menard and Brunet 2011; Cowen and Hodgson 2015). As a result, the strategies used for regulating and improving MSSMs' identity at work through viable and sustainable models of operation are relatively missing in this context. This is particularly true when one considers the absence of previous studies that have explored the linkages of service operations designs and the construct of MSSMs' work identity. Stemming from all this, this paper is an attempt to close this gap, using the lens of identity theory, an approach that remains largely neglected in manufacturing support services design literature. It is argued in this paper that the idealised MSSMs' work identity is difficult to realise without an appropriate operations structure that potentially reduces passing pressures, stress, and risks to managers. This study explores the impact of creating an appropriate service operations design using systems approach on the development of MSSMs work identity and behaviour. It is demonstrated in this study that the systems thinking approach for service operations design is an enabler for promoting dramatic changes to the role of MSSMs in the workplace with significant reduction in levels of stress and work 
pressures traditionally experienced in such departments. These dramatic changes are resembled by the creation of a transformational management style, changing the role of MSSMs from employees' monitors to supporters, and adoption of new discursive practices that are embracing more people-centred perspective.

The paper draws on a multiple-case study in three Palestinian manufacturing organisations, post the systems thinking approach adoption in their manufacturing support services. This research design is deemed most appropriate as case studies provide an in-depth understanding into rarely-studied phenomena, such as the impact of service operations designs on MSSMs' self-identity, within a real-life context (Yin 2009). The paper aims to contribute to theory by adding for the first time a discussion of manager's identity theory to the service operations design literature in a manufacturing context. Second, the paper introduces an interesting theorization of manager's identity with systems thinking methodology that emphasizes holistic, multi-disciplinary, and integrative characteristics of the service system. Third, through an empirical study of MSSMs within three Palestinian manufacturing organisations, the paper offers a novel aspect of building a service operations design that can engage managers in maintaining a coherent and valued self-identity.

The remainder of this article begins with a literature review of the concept of identity and work identity theories, followed by introducing the systems thinking methodology for service operations design. Next, the multiple-case study methodology is explained, before the findings are presented. Finally, findings are discussed and conclusions drawn.

\section{Identity theory: paving the way for work identity}

Identity is an important pillar in someone's life as it shapes how people see him and how he sees others; it also dictates how an individual thinks and behaves (Alvesson, Lee Ashcraft, and Thomas 2008; Cowen and Hodgson 2015). According to Watson (2007, 136), 
identity is defined as "the notion of who or what a particular person is in relation to others". Identity is, therefore, inherently social, as individuals need to be part of something wider than themselves to be able to answer the question "who am I" (Sveningsson and Alvesson 2003; Adams and Crafford 2012). The self-aspect of the individual identity must therefore be continuously reshaped and modified relative to the context of a group. In other words, other people play an important role in the construction of the individual's identity (Vidaillet and Vignon 2010). However, due to the fact that workplace constitute an exceptional social context where people negotiate and formulate identity (Brown 2015), a broad and influential stream of research across the social sciences has regarded work identity theory as a way in which the processes of construction of a valuable and valued identity at work can be unpacked. According to Walsh and Gordon (2008), the definition of work identity is "a work-based self-concept constituted of a combination of organisational, occupational and other identities that shapes the roles a person adopts and the corresponding ways he or she behaves when performing his or her work" in the context of their jobs and/or careers. Similarly, Agostino (2004:26) explains that work identity is "the sense of individual identity that an employee derives from being part of a particular workplace". Based on these definitions, it can then be discerned that work identity is an underlying prerequisite for healthy and productive individuals in their workplace (De Braine and Roodt 2011). It is as Kirpal (2004) illustrates that the successful construction and maintenance of an identity at work enhances managers' feeling of belonging to their organisation. Further, strong work identity has a significant positive impact on managers' behaviour, which in turn help improve work outcomes and overall organisational performance (Amiot et al. 2007; Wayne, Randel, and Stevens 2006).

Within the context of this paper, work environment offers critical social and work facets where development of managers' identity is essential, particularly in high-demand jobs with stressful work patterns (Adams and Crafford 2012). Social facets, in this sense, include work 
groups, teams, and the interactions at an organisational level. Whereas, work facets describe workplace offerings and structures that are used by managers to derive their identities through identity formation processes. During the identity formation process, managers rely upon certain workplace norms, meanings, values and beliefs, and core working principles in shaping their work identity. Consequently, these workplace facets serve as behaviour guides (Bothma, Lloyd, and Khapova 2015). Based on this, work identity for managers is multi-layered and multidimensional construct that depicts how managers interact within their employment environment (Buche 2006). According to Bothma, Lloyd, and Khapova (2015), work identity, including managers, can be constructed and maintained at three different levels, namely, a structural, social and individual-psychological level. At the structural level, the work identity develops through patterns of employment, characterised by the way employees are managed, and customer-care philosophy used. This level also includes all aspects of workplace culture, such as principles of work, and manager-employees relationships. The social level involves creating work identity through interaction between the employee and other work groups and careers. Finally, the individual-psychological level is where work identity can be built through employee's attitude towards work, perception of the work content, level of career or professional development, occupational history, work centrality and employee-environment fit. This perspective of Bothma, Lloyd, and Khapova (2015), for constructing and maintaining a work identity, suggests that a critical mind-set in organisations is needed to regulating and improving work identity of manager, who are typically under significant work pressure and stress, through viable and sustainable models of operation that can embrace all these three structural, social and individual-psychological levels. This notion is asserted by Cowen and Hodgson (2015) who found that pressure and demanding working life of project managers may lead to the project manager experiencing a temporarily damaged identity at work that can be restored by organisational based coping strategies. In the same vein, Anderson (2010) explains 
that management thinking of concentrating on what managers need to know in a demanding job environment is no longer enough, and that a major business operational modernisation and organisational structural interventions towards 'who managers need to be' are required. Similarly, Adams and Crafford (2012) call for introducing novel strategies of investment in managers through significant changes to the work environment and operational systems to develop managers' identity at work.

\section{Systems thinking design}

Nowadays, systems thinking methodologies are witnessing acceptance in many manufacturing industries around the globe as a possible strategy to face increasing job demands, intensive economic pressures to reduce costs, and ever changing customer expectations (Jackson 2009). This acceptance embraces a systems view to model the complexity of manufacturing support services' operations (Jaaron and Backhouse 2011). Systems thinking, this way, help managers understand how the various elements of a manufacturing support services systems, including people, networks of actors, and supporting infrastructure, may all be seen as a connected whole. In a complex and dynamic environment, such as manufacturing support services, there are many managers who tend to design several parts of the system separately to provide an overall service solution (Seddon 2008). This will develop a service system where managers need to manage the parts in order to control the whole (Darzentas and Darzentas 2014). Ackoff (1981) found that reductionist approach of managing system parts without understanding the interaction between them is a main cause for system failure. Seddon (2008) also asserted that reductionist approach generates silo mentality which hampers necessary interaction in and around the system. In response to the need for new innovative approaches to design manufacturing support services, while considering the so called wholeness, dynamics, and connectedness of the system, Seddon (2003) brought out a new 
systems thinking methodology for designing service operations in organisations, including manufacturing firms. This methodology is based on principles of soft systems methodology developed by Peter Checkland (1981), the systems theory of Ohno (1988), and the intervention theory of Deming (1982). The term "Systems thinking" will be used to describe this service operations design methodology throughout this paper.

According to Seddon (2003), systems thinking methodology articulates a structured process where service operations are strictly designed around customer demands and wants, and not around the functional hierarchies or silo working. Therefore, major changes in the organisation culture are required; that is characterised by the formulation of self-organising multifunctional teams who can deliver what the customer wants when and where needed. To make this possible, team members are front-line employees from the workplace itself as they will also be responsible for leading the systems thinking redesign intervention into service operations (Jackson, Johnston, and Seddon 2008). As a main principle in this systems thinking methodology, team members are encouraged by their managers to explore what matters to customer the most, and what they really want from the system from a customer point of view. To accomplish this, team members with the support of their managers spend a considerable amount of time studying the demand received by the service department at all points of contact over a period of time. This will allow classification of demand studied into two types; value demand and failure demand (Seddon 2003). Value demand is what the service department has been established to serve and what the customers want which is of value to them, and failure demand is the demand that the service department was not able to serve due to the lack of information, system, or supporting operations. Another main principle in the systems thinking methodology is the removal of waste found in traditional service processes. At this stage, team members map the flow of work for each service operation from initial point of contact to completion including various steps, decisions points, and any waste found. To make this 
process as realistic as possible, all related organisational policies, rules and budgetary requirements, also known as system conditions, are considered and revised with the support and advice of employees' manager. Shaping the role of managers, this way, will provide a service system that is highly responsive to customers, and will significantly reduce failure demand frequency based on integrating managers' experiences in the redesign process. It is as stated by Jackson, Johnston, and Seddon (2008), integrating managers' experiences and support during redesigning a service operation, is significantly important as it moulds what manager's needs to be at the workplace. However, these systems thinking principles of redesigning service operations are illustrated in Figure 1 in a conceptual framework.

For this type of work, team members are empowered and trusted to make decisions on the work they have in hands. They also enjoy open channels of communication with their peers and with other teams and departments where necessary to share knowledge and information (Darzentas and Darzentas 2014). It is due to this virtue that team members become self-directed by reflecting on the system operations they have, and then learning how to make their own rules and decisions to absorb work environment changes (Dunnion and O'Donovan 2014). Service operations, this way, become under more control as the data is in the hands of the people doing the work. Therefore, service systems witness a dramatic shift in the role of managers from being more of a command-and-control one to more of supporters and helpers. Systems thinking methodology requires employees who can steer the work rather than being steered (Jackson 2009). Managers this way enjoy a more relaxing working environment where they concentrate on whether their experience and support is needed by team members. The new role of managers includes more job control as they become part of the workforce as they have the capability, and on occasions can act on this capability. Therefore, system thinking methodology is based on the promotion and respect of human values (Jackson, Johnston, and Seddon 2008). 


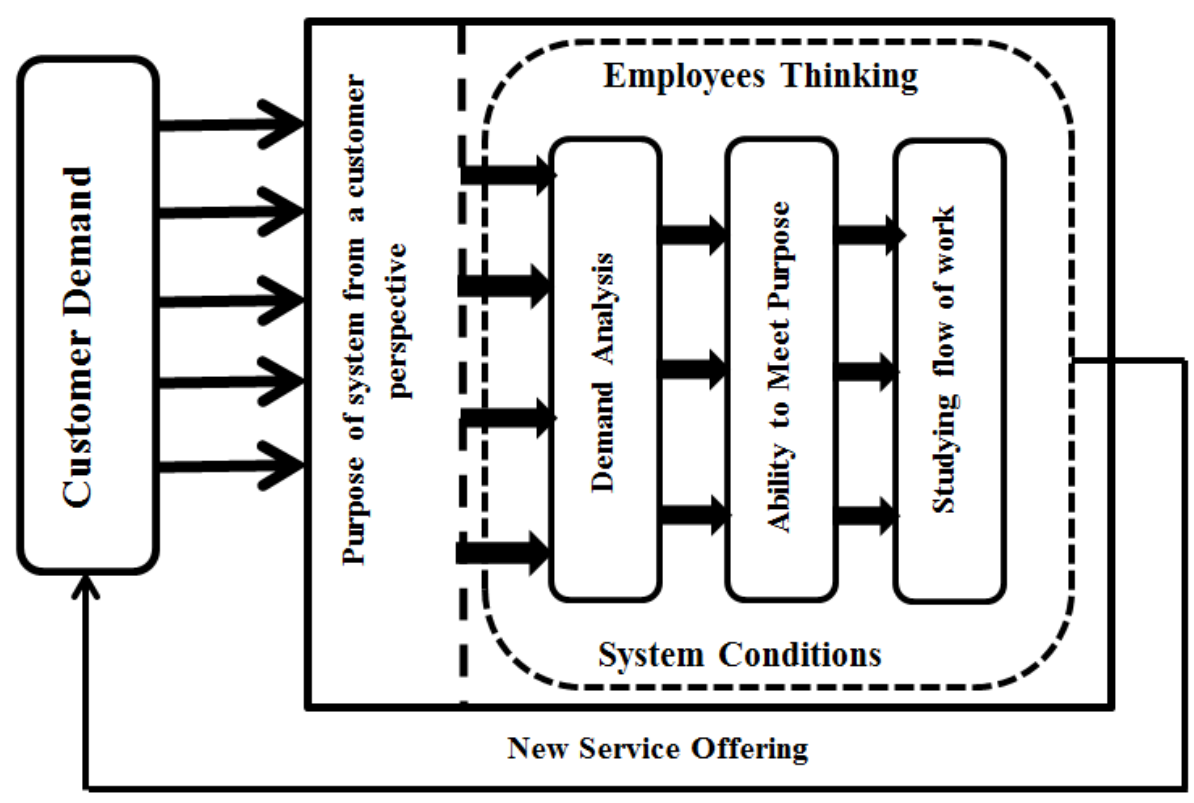

Figure 1. Conceptual framework of the systems thinking methodology

\subsection{Systems Thinking Methodology in Practice}

To translate the above methodology into practice, this sections aims at presenting three main practical steps of "check-plan-do", that are used in redesigning service operations based on systems thinking principles. These steps are summarised in Table 1, and further explained below.

Table 1 Three stages of systems thinking methodology (Jackson, Johnston, and Seddon 2008)

\begin{tabular}{lll}
\hline \hline Stages in process & What is it? & What does it do? \\
\hline \hline 'Check' & $\begin{array}{l}\text { An analysis of the what } \\
\text { and why of the current } \\
\text { system }\end{array}$ & $\begin{array}{l}\text { Provides an understanding of the system as it is and } \\
\text { identifies waste and the causes of waste. 'Check' asks: } \\
\text { What, in reality, is the purpose of this system? What is } \\
\text { the nature of customer demand? How does the work } \\
\text { flow? What is value work and what is waste? Why does } \\
\text { the system behave like this? }\end{array}$ \\
& $\begin{array}{ll}\text { Exploration of potential } \\
\text { solutions to eliminate } \\
\text { waste }\end{array}$ & $\begin{array}{l}\text { Provides a framework to establish what the purpose of } \\
\text { the system should be and how the flow of work can be } \\
\text { improved to meet it. 'Plan' asks: What is the purpose of } \\
\text { the system from the customer's perspective? What needs } \\
\text { to change to improve performance against purpose? } \\
\text { What measures are necessary in order to gauge }\end{array}$ \\
& $\begin{array}{l}\text { improvement? } \\
\end{array}$
\end{tabular}


‘Do'

Allows for the testing and gradual introduction of changes whilst still considering further improvement. Develop redesigns with those doing the work, Experiment gradually, Continue to review changes, Work with managers on their changing role.

The process of applying the systems thinking methodology in service operations design follows three main steps. The first step is the 'Check' stage where a special team from frontline employees analyse customer demand to understand why the system is behaving in such a way that failure demand is received. Once the team understands the purpose of the system from a customer point of view, and the type of demand received, it can then start to map the flow of processes in the system (Dunnion and O'Donovan 2014). A flow chart of each operation in the workplace is developed to identify waste present in the system and potential blockages of delivering value demand (Seddon 2008). All processes classified as waste are marked in red on the process flow chart. While processes that add value from a customer's point of view are marked in green. The check stage usually shows managers the failing of their system, and provides an evidence for the need to change their views and the way they think about their employees (Seddon 2003). The second step is the 'Plan' stage where all possible solutions are explored to better design flow of operations against customer demand. Based on what has been learned from previous stage, the team maps out the new service operations. Team members at this stage are typically focused on minimizing non-value adding activities from a customer point of view. This is followed by building performance measures for the newly designed operations. This is usually how good employees are in creating a value demand and the percentage of value demand out of the total demand received (Dunnion and O'Donovan 2014). The final step is the 'Do' stage of experimenting newly designed service operations by the intervention team. Once the new operations are tested and approved, a gradual roll-in of frontline employees doing the work is performed with careful observation of both employees' 
reaction to it and customers feedback. If needed, the operations are re-designed and re-tested again to make sure the customer get the best possible service. This is the slowest stage among the three stages as the aim is to "do it right rather than do it quick" (Jackson, Johnston, and Seddon 2008). However, to make the continuous improvement of the system possible, and also to ensure the identification of new demands coming in to the service systems, the "check-plando' process is a continuous process (see figure 2).

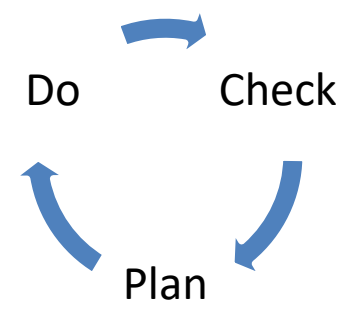

Figure 2 Check-Plan-Do cycle.

\section{Methodology}

Due to the exploratory nature of this research, a qualitative multiple-case study approach was applied. The rationale behind this approach selection is that case studies are attractive research design due to their heuristic value (Levine 1996). They go beyond the level of thick contextual descriptions of a situation (Kyburz-Graber 2004). For instance, they are more suitable for situations where theoretical connections are needed to be generated (Macpherson 2000). Yin (2009) explains that carrying out, at least, two and more case studies can have stronger analytical generalisation from findings, and will produce more valid findings to achieve research objectives. Therefore, multiple-case studies were chosen in this research. Using theoretical sampling techniques as the selection process for inductive research (Denzin 1978), five different Palestine-based manufacturing organisations, unevenly applying the systems thinking principles into their manufacturing support services operations, were initially 
chosen as possible candidates for this study. However, in order to find out the cases with the strongest and most positive examples of the phenomena (i.e. fully applying systems thinking methodology principles into their service operations) under investigation (Yin 2009), intensity sampling technique (Miles and Huberman 1994) was applied. This two-level criterion for the selection of the most appropriate cases was possible due to the availability of a binding memorandum of understanding between the author's institution and a local corporate group (anonymised) composed of six manufacturing organisations. This close collaboration with the corporate group provided access to key informants at managerial levels in all three selected cases.

The first case study (i.e. Manufacturer A) is specialised in the production of plastic pipes and water and juice bottles of different shapes and sizes. In addition to its manufacturing production, the company has a commercial department to import water network pieces and other plastic goods that are sold alongside the company's products. The second case study (i.e. Manufacturer B) is a major producer of corrugated carton boxes and containers with a maximum production capacity of almost 8 tons per hour. The third Case study (i.e. Manufacturer C) is a leading company, in the West Bank region, specialized in manufacturing of all kinds of pelleted animal feed. The factory is a home for latest tech computer controlled equipment and horizontal puddle mixer. All of these three case organisations went through a change management programme mandated by the corporate group in early 2014; based on systems thinking principles to redesign their service operations departments' method of working. The service operations departments were designed such that front-line employees would never pass-on the customer, but where further input was required then another front-line employee with better experience in the specific area of demand was brought into a conference call. Customers, this way, experienced personal service. Further description of each case study is provided in Table 2. 
Table 2 case study organisations and their details.

\begin{tabular}{llll}
\hline \hline Item & Manufacturer A & Manufacturer B & Manufacturer C \\
\hline \hline Core Business & Plastic Industries & $\begin{array}{l}\text { Corrugated Cartons and } \\
\text { Packaging Industries } \\
\text { Typical Products }\end{array}$ & Animal Feed Industries \\
& $\begin{array}{l}\text { Plastic pipes, water and } \\
\text { juice bottles of different } \\
\text { sizes and shapes, drip } \\
\text { irrigation pipes, and } \\
\text { greenhouses covers and } \\
\text { accessories. }\end{array}$ & $\begin{array}{l}\text { foodstuff, fruits and } \\
\text { vegetables, and others. }\end{array}$ & $\begin{array}{l}\text { Producing all types of } \\
\text { animal feed using } \\
\text { vegetarian raw materials } \\
\text { (grains) only. }\end{array}$ \\
& Approx. 110 employees & Approx. 60 employees & Approx. 35 employees \\
\hline \hline
\end{tabular}

Data collection in this study was mainly conducted through semi-structured interviews, focus groups, and extractions from both observations and documents collected. A case study protocol (Yin 2009) was used during the semi-structured interviews. This protocol used inputs from service operations, systems thinking, and identity theory literature. Four to six semistructured interviews lasting one hour on average were performed at each case organisation, resulting in a total of 15 interviews. Interviewees were manufacturing support services' managers in three case organisations. Interviews were tape recorded and transcribed as soon as the interviews were completed in preparation for the analysis stage. However, in order to reduce the scope of bias inherits in relying on inputs provided by one group of people (i.e. service managers), and to provide an opportunity to refine findings of interviews analysis, focus groups method was also used. One focus group at the size of five service managers, from the three case organisations, was requested to comments on the initial findings of analysing semistructured interviews. Matthyssens and Vandenbempt (1998) regarded this process as essential for the final refinement and reliability of the results. To further increase results validity and reliability, observations and documents collection helped in confirming things discussed with interviewees. 
The analysis of data collected involved sending back the transcribed interviews from each case organisation for interviewees for validation. This was done in order to ensure that no misunderstandings took place during transcription of interviews (Gibbert, Ruigrok, and Wicki 2008). Subsequently, qualitative analysis software was used to double-code the transcripts from each case study separately. The use of the software allowed for updating the codes throughout the coding process. Based on this, it was possible to divide the interview transcripts into meaningful parts, and every part was given a code that belongs to a pre-defined topic (Miles and Huberman 1994). At this stage, it was necessary to find codes with similar topics. Similar topics are clustered around larger central themes that were used later for interpretation. This single-case analysis process was completed by sending the results to each case organisation once again as a necessary requirement for empirical validation (Miles and Huberman 1994). Consequently, cross-case analysis was possible by performing a comparative overview of results for pattern matching following the guidelines of Yin (2009). The aim of this stage was to identify distinct tactics and practices, emanating from systems thinking methodology offerings, through which manufacturing support services' managers developed and maintained their work identity. Furthermore, to condense the cross-case data it was necessary to apply "Within-category sorting" and "cross-category clustering" techniques. Eventually, this had led to the generation of "summary tables" recommended by Miles and Huberman (1994). These results are illustrated in Table 3 below. Finally, the results were then interpreted against related literature to find out how these findings are supported or conflicted with previous studies. 
Table 3 Work identity development-related changes

\begin{tabular}{|c|c|c|}
\hline Codes & Topics discussed & Central themes \\
\hline $\begin{array}{l}\text { - Authentic leaders } \\
\text { - Management skills } \\
\text { - Team process } \\
\text { - Agility }\end{array}$ & $\begin{array}{ll}\text { - } & \text { Focus is beyond skills development. } \\
\text { - } & \text { Ability to become agile to assess and } \\
\text { redirect as needed. } \\
\text { - } \\
\text { Inspiring team members to change } \\
\text { perceptions and motivations to work } \\
\text { towards common goals. }\end{array}$ & $\begin{array}{l}\text { Creation of transformational } \\
\text { management style }\end{array}$ \\
\hline $\begin{array}{l}\text { - Job evaluation } \\
\text { - Role } \\
\text { - Behaviour changes } \\
\text { - support }\end{array}$ & $\begin{array}{l}\text { - General moral system of the } \\
\text { workplace controls the human } \\
\text { resources behaviour. } \\
\text { - Job target achievement is no longer } \\
\text { used. } \\
\text { - Focus is on helping employees } \\
\text { improve the system. }\end{array}$ & $\begin{array}{l}\text { Departure from monitoring } \\
\text { to supporting }\end{array}$ \\
\hline $\begin{array}{l}\text { - discursive } \\
\text { practices } \\
\text { - Humanistic } \\
\text { approach }\end{array}$ & $\begin{array}{l}\text { - Shared understanding dialogue } \\
\text { - } \quad \text { Nature of teamwork dialogue } \\
\text { Employees' ownership and its } \\
\text { importance. } \\
\text { - More humanistic approach to helping } \\
\text { team members to understand } \\
\text { strengths and weaknesses. }\end{array}$ & $\begin{array}{l}\text { Adoption of new discursive } \\
\text { practices }\end{array}$ \\
\hline
\end{tabular}

\section{Results}

\subsection{Creation of transformational management style}

Analysis of the results has indicated that there was a definite shift in the role of MSSMs towards a transformational management style. It is revealed by analysis that the systems thinking approach adopted in service operations departments of case organisations has introduced managers' role as being more about relational process with their employees. Managers are now understood as a type of person that challenges the status quo by encouraging their employees to explore new ways of dealing with customer demands. Thus, manager are now more prepared to learning new things. Furthermore, the results show that the new management style of managers involves offering support through keeping lines of communication open with team members. Managers' new work identity, therefore, include 
sharing ideas and experiences with employees who in return provide solutions for the problems in hands. It is as stated by MSSM at 'Manufacturer B': 'I lead quite interesting team in here, they discuss with me how we can improve our service on periodical basis and also whenever there is an opportunity that we should not miss....I usually make it clear to the team that they can talk to me anywhere, in my office, in the corridor, or even when I'm passing by their desk....most importantly we must work together to help our customers". Analysis also indicated that this type of relationship has helped managers develop and maintain trust with their employees, which is, in their view, a top priority to inspire team members and motivate them to be productive.

\subsection{Departure from monitoring to supporting}

The results asserted that the systems thinking approach for service operation design has brought numerous improvements to MSSMs. It was found that the new working philosophy has shifted MSSMs focus from conventional operations measures monitoring (i.e. monitoring targets and statistics) towards the percentage of one stop resolution, or how good employees are in helping the customer achieve his demand during the first interaction. Therefore, MSSMs behaviour is changed from monitoring targets of the workplace to supporting employees to deliver value work to customers. This entails that managers' demand for targets achievement is no longer in place. A MSSM from 'Manufacturer A' commented: "we now understand that giving the customer what he wants from the first time of contact is the best strategy to work, and also the best strategy to evaluate our people.... I spend considerable amount of time just watching team members performance of receiving and processing demands exactly as the customer wants...this is what I use to evaluate good job, not how many transactions they produce everyday”. However, this MSSM's behaviour of supporting value work delivery has produced automatic productivity improvement as customers do not need to contact the company again, which allowed service operations department to handle more demands during 
peak times. The results also suggest that this behaviour change has allowed MSSMs to focus on the main purpose of the manufacturing service operations (i.e. supporting customers and production) rather than maintaining the system against failures. It is as stated by one of the MSSMs at 'Manufacturer C': "we spend more time taking to our farmers now to capture what exactly their needs are before logging their orders into the system.... by listening to farmers we save efforts and time, and thus we have time to focus on other demands and work issues".

\subsection{Adoption of new discursive practices}

According to analysis, it is reasonable to consider the significant role of discursive practices of working in understanding development of MSSMs work identity in this study. It was clearly found through results that MSSMs have adopted new discursive practices since the advent of the systems thinking approach into the design of their service operations. This is delineated by having continuous conversations with team members about the nature of teamwork and how shared understandings and values can contribute to effective performance. MSSMs also used expressions in their conversation that instil feelings of empowerment and ownership of workplace among team members. According to a MSSM at 'Manufacturer B': "we now speak different language with team members...our tone is different, the way we look at them is different... we know that they are closer to customers than us...we give them freedom to do what is necessary to help customers and win the business... you only have a good a team when you give them capacity to change things". Furthermore, MSSMs' discursive shifts have embraced a softer, more people-centred perspective. These new discursive shifts have granted greater awareness of the role of teamwork in bringing in mutual respect and understanding. In addition to talking about the value of teamwork, MSSMs also offered their views about their role by using a more generic language that reflects cooperation and partnership with team members; away from valuing transactional side of the work. One of the interviewees at 'Manufacturer A' commented: “They (i.e. team members) are real partners for a successful 
business...I respect their views and in return they respect me more as I adopt their views in some case on how things should be made here...we value their thoughts because they are the people doing the work...I am much happier now as I do not feel the pressure of being always responsible for providing solutions for problems; my team members do this now and I only help in directing them on how their solutions can be put into practice”. However, these discursive practices were observed across all MSSMs interviewed.

\section{Discussion and Conclusion}

To date, research efforts that investigate service operations design methodologies, based on systems thinking principles, and work identity of service managers in manufacturing sector are absent. This can be elicited from previous studies that have overlooked the need for MSSMs to learning how they fit their role for an eventual realisation of their self-potential through proper organisational structural and operational fittings (Menard and Brunet 2011; Cowen and Hodgson 2015). The aim of this paper was, therefore, to explore the impact of designing service operations using systems thinking approach on the development of MSSMs work identity and behaviour. The results achieved from cross-case analysis have demonstrated that dramatic changes to the role of MSSMs can be brought in by systems thinking approach for service operations design. These changes are characterised by the creation of a transformational management style, focusing on employees' support rather than monitoring, and adoption of new discursive practices that are embracing more people-centred perspective.

In this study, it was found that systems thinking methodology has created a transformational management style in the workplace. MSSMs are explicitly possessing motives to communicate shared values, discussing new ideas using inclusive language (e.g. "we" and "us"). This transformational behaviour has been found by Johnson et al. (2012) as positively linked with building leaders collective identities (i.e. self-definition of manager is 
based on group membership) at work. Arguably, systems thinking approach, this way, allows MSSMs to internalise values and norms that are embraced by their group (i.e. team members), successfully increasing managers' claims on their leadership roles, and increasing likelihood that they will be endorsed by their team members. Managers with strong transformational behaviour regard close interpersonal relationships with followers as primary antecedent for managers' self-definition. The results suggest that such transformational managers offer support to their team members when exploring new ways of doing the work; which is particularly appealing to followers and significantly beneficial for reflecting managers' selfesteem. This is supported by the work of Sluss and Ashforth (2007) who explained that taking into considerations followers' needs for help (i.e. offering them support at work) is the ultimate way through which managers derive their self-worth. Based on this, it can be discerned that the new design for service operations has performed as a proxy for raising MSSMs to a higher level of redefining their work identities, enabling them to surpass their personal interest for the teams' welfare, and ultimately for the organisations' welfare. Furthermore, systems thinking approach has also brought in new forms of participation within the existing human resources at the manufacturing support services departments of case organisation. This is evident in the new role played by MSSMs of departing away from mere monitoring of operations measures towards supporting value work delivery. Angot, Malloch, and Kleymann (2008) regarded changing forms of participation of managers within existing workforce, such as those associated with work design interventions, provide opportunities for managers to reshape, form, improve, and regulate their identities (i.e. identity-work). This process of supporting value work delivery can be understood as one of identity formation technique whereby a MSSM becomes involved in a process of transforming the self through participation in service delivery activities. However, MSSMs' identity formation, in this context, is different from the process of knowledge acquisition or development of competencies. While knowledge and 
competencies acquisition can be enhanced through cognitive learning and practicing, identity formation requires a state of being that can only be realised through considerable identity-work (Warhurst 2011).

In terms of MSSMs going through a discursive shift as a result of applying the systems thinking methodology into the design of manufacturing support service operations, the results indicate a change in the language which constructs identity. For example, MSSMs described themselves as partners with their followers. They also used expressions such as shared understanding, work values, and employee empowerment as being principles of work. According to Alvesson, Lee Ashcraft, and Thomas (2008), these discursive practices play a crucial role in shaping and controlling work identity when practiced by managers. This is mainly due to the fact that discourse style usually prompts identity-work. Consequently, work identity of MSSMs has been constituted by the work contextual offerings through drawing significant discourses and discussions that maintain the basis of identity construction (i.e. the process of identity restoration). The evidence here strongly supports the notion that changing managers' role to become more of supporters has positively fuelled MSSMs identity-work. The results show that this has activated a number of work principles and values centred on people trust and mutual respect. Kornberger and Brown (2007) have explained that the notion of principles and values at work are some of the main discursive resources on which manager rely to accomplish their identity work. These findings differs from existing literature on managers' work identity and discursive practices, where the offerings of this discursive practice shift, based on systems thinking methodology, has participated in the creation of collective identity of MSSMs of viewing managers as part of their followers. However, previous studies on this topic have shown that employees drew opposing discourses in constructing their identities as 
they have failed to see mutual values that could bond them with their managers (Clarke, Brown, and Hailey 2009).

This study has important research and practical implications that benefit service operations and identity theory research in several ways. First, the paper briefly revises the wide spectrum of identity theory literature with the hope of providing more interest into the human side of MSSMs' life. The author illustrate the ways in which MSSMs identity is restored, focusing on certain aspects of workplace offerings that activate intense forms of identity work on the part of their managers. Second, the paper contributes to theory by adding for the first time a discussion of manager's identity theory to the service operations design literature in a manufacturing context. It provides insights into the service operations designs that manufacturing organisations can use to regulate, negotiate, and improve managers' work identities. In other words, the alternative service design model presented here has the potential to mitigate some of the effects of the traditional mechanistic models widely implemented in these strategic departments (Jaaron and Backhouse 2011). Third, the paper introduces an interesting novel theorization of manager's identity with systems thinking methodology that emphasizes holistic, multi-disciplinary, and integrative characteristics of the service system. In particular, the paper not only employs principles of systems thinking methodologies for the development of managerial skills and functional aspect of the role, but it also provides a distinct approach on the creation and maintenance of organisational climates that will encourage effective manager behaviour. Fourth, through an empirical study of MSSMs within three Palestinian manufacturing organisations, the paper offers a novel aspect of building a service operations design that can engage managers in maintaining a coherent and valued self-identity. 


\section{Limitations and Future Research Work}

Despite the fact that the findings in this study are supported by the empirical evidence and validation, there is still a need to consider these findings in light of a number of limitations. First, the data comprised informants working in the manufacturing sector of a non-western setting. Data collected from other informants working in other settings or industries may yield different findings. Therefore, future research work may seek to validate the study findings using different samples from different settings and cultures to ensure that the effect of these two constructs (i.e. industry type and culture) does not confound findings. Second, to the best of the author knowledge, previous research that links service operations design, based on systems thinking principles, and manager's identity at work is absent. This has limited the study's ability to propose grounded theory development (Cooper and Emroy 1995) using the findings reported here. Third, this study did not include 'before and after' quantitative comparisons of the MSSMs' work identity changes as a result of the new service operations design. Future research is, then, needed to conduct longitudinal studies to document changes in MSSMs' work identity patterns due to structural changes in the workplace. Nonetheless, while the findings reported here might lack statistical generalisability, the richness of details provided gives the study a degree of "credibility and plausibility" (Parry 1999, 150).

\section{References}

Ackoff, R.L. (1981), Creating the Corporate Future. New York: John Wiley and Sons.

Adams, B. G. and Anne Crafford (2012), "Identity at work: Exploring strategies for identity work," South African Journal of Industrial Psychology, Vol.38 No.1, pp. 1-11.

Agostino, J. (2004), "Workplace Identity," Doctoral Dissertation, Business Administration, Swinburne University of Technology, Hawthorn, Victoria, Australia.

Al-Mutairi, S.G., Burns, N.D., and Backhouse, C.J. (2005), "Using a Viable System Model as a Diagnostic Tool for Small-Sized Companies," International Journal of Services and Operations Management, Vol.1 No.3, pp. 220-238. 
Alvesson, M., Lee Ashcraft, K., and Thomas, R. (2008), "Identity Matters: Reflections on the Construction of Identity Scholarship in Organisation Studies," Organisation, Vol.15 No.1, pp. 5-28.

Amiot, C.E., De la Sablonnière, R., Terry, D.J., and Smith, J.R. (2007), "Integration of Social Identities in the Self: Toward a Cognitive-Developmental Model," Personality and Social Psychology Review, Vol.11 No.4, pp. 364-388.

Anderson, L. (2010), "Talking the Talk' - A Discursive Approach to Evaluating Management Development," Human Resource Development International, Vol.13 No.3, pp. 285-98.

Angot, J., Malloch, H., and B. Kleymann (2008), "The Formation of Professional Identity in French Apprenti Managers,” Education+Training, Vol.50 No.5, pp. 406-22.

Bothma, F.C., Lloyd, S., and Khapova, S. (2015), "Work Identity: Clarifying the Concept," in Conceptualising and Measuring Work Identity: South-African Perspectives and Findings, Jansen, P. and Roodt, G., eds. Springer, New York, 23-51.

Brown, A.D. (2015), "Identities and Identity Work in Organizations," International Journal of Management Reviews, Vol.17 No.1, pp. 20-40.

Buche, M. W. (2006), "Gender and IT Professional Work Identity," in Gender and IT encyclopaedia, E. Trauth, eds. University Park: Information Science Publishing, 434439.

Checkland, P. (1981), Systems Thinking, Systems Practice. Chichester: Wiley.

Cowen, M., and Hodgson, D. E. (2015), "Damaged Identities: Examining Identity Regulation and Identity Work of Gulf Project Managers," International Journal of Project Management, Vol.33 No.7, pp. 1523-1533.

Clarke, C. A., Brown, A. D., and Hailey, V. H. (2009), "Working Identities? Antagonistic Discursive Resources and Managerial Identity," Human Relations, Vol.62 No.3, pp. 323-352.

Cooper, R.D., and Emroy, C.W. (1995), Business Research Methods. Fifth ed. Homewood, IL: Richard D. Irwin.

Darzentas, J., and Darzentas, J. (2014), "Systems Thinking in Design: Service Design and SelfServices," FORMakademisk, Vol.7 No.4, pp. 1-18.

De Braine, R., and Roodt, G. (2011), "The Job-Demands-Resources Model as Predictor of Work Identity and Work Engagement: A Comparative Analysis," SA Journal of Industrial Psychology, Vol.37 No.2, pp. 1-11.

Deming, W.E. (1982), Out of Crisis, Cambridge: Cambridge University Press.

Denzin, N.K. (1978), The Research Act, 2nd ed. New York: McGraw-Hill.

Dunnion J., and O'Donovan, B. (2014), "Systems Thinking and Higher Education: the Vanguard Method," Syst Pract Action Res, Vol.27 No.1, pp. 23-37.

Fish, A.J. (1985), “The Manager's Identity,” Asia Pacific Journal of Human Resources, Vol.23 No.4, pp. 23-27.

Gadinger, M.C., Fischer, J.E., Schneider, S., Terris, D.D., Kruckeberg, K., Yamamoto, S., Frank, G., and Kromm, W. (2010), "Gender Moderates the Health-Effects of Job Strain in Managers,” Int. Arch. Occup. Environ. Health, Vol. 83 No.5, pp. 531-541.

Gibbert, M., Ruigrok, W., and Wicki, B. (2008), "What Passes as A Rigorous Case Study?," Strategic Management Journal, Vol.29 No.13, pp. 1465-1474.

Jaaron, A., and Backhouse, C.J. (2011), "A methodology for the Implementation of Lean Thinking in Manufacturing Support Services," Int. J. Services and Operations Management, Vol.9 No.4, pp. 389-410.

Jackson, M.C. (2009), "Fifty Years of Systems Thinking for Management," Journal of the Operational Research Society, Vol.60 No.1, pp. S24-S32.

Jackson, M.C., Johnston, N., and Seddon, J. (2008), "Evaluating Systems Thinking in Housing," Journal of the Operational Research Society, Vol.59 No.2, pp. 186-197. 
Johnson, R. E., Venus, M., Lanaj, K., Mao, C., and Chang, C. H. (2012), "Leader Identity as an Antecedent of the Frequency and Consistency of Transformational, Consideration, and Abusive Leader Behavior," Journal of Applied Psychology, Vol.97 No.6, pp. $1262-1272$.

Kirpal, S. (2004b), "Work Identities of Nurses: Between Caring and Efficiency Demands," Career Development International, Vol.9 No.3, pp. 274-304.

Kornberger, M., and Brown, A.D. (2007), "Ethics' as A Discursive Resource for Identity Work," Human Relations, Vol.60 No.3, pp. 497-518.

Kyburz-Graber, R. (2004), "Does Case-Study Methodology Lack Rigour? The Need for Quality Criteria for Sound Case-Study Research," Environmental Education Research, Vol.10 No.1, pp. 53-65.

Levine, J.P. (1996), "The Case Study as A Jury Research Methodology," Journal of Criminal Justice, Vol.24 No.4, pp. 351-360.

Macpherson, I. (2000), "Case Study in the Contemporary World of Research: Using Notions of Purpose, Place, Process and Product to Develop Some Principles for Practice," International Journal of Social Research Methodology, Vol.3 No.1, pp. 49- 61.

Matthyssens, P., and Vandenbempt, K. (1998), "Creating Competitive Advantage in Industrial Services," The Journal of Business and Industrial Marketing, Vol.13 No.4/5, pp. 339355.

Menard, J., and Brunet, L. (2011), "Authenticity and Well-Being in the Workplace: A Mediation Model," Journal of Managerial Psychology, Vol. 26 No.4, pp. 331-346.

Miles, M. B., and Huberman, A. M. (1994), Qualitative Data Analysis: An Expanded Sourcebook, $2^{\text {nd }}$ ed. Thousand Oaks: Sage Publications.

Ohno, T. (1988), Toyota Production System: Beyond Large-Scale Production, New York: Productivity Press.

Parry,K.W. (1999), "Enhancing Adaptability: Leadership Strategies to Accommodate Change in Local Government Settings," Journal of Organizational Change and Management, Vol.12 No.2, pp. 134-56.

Phusavat, K. (2008), "Future Competitiveness: Viewpoints from Manufacturers and Service Providers," Industrial Management \& Data Systems, Vol.108 No.2, pp. 191-207.

Rai, S., and Kumar, V.V. (2012), "Five Factor Model of Personality and Role Stress," The Indian Journal of Industrial Relations, Vol.48 No.2, pp. 341-353.

Seddon, J. (2008), Systems Thinking in the Public Sector, Axminster: Triarchy Press.

Seddon, J. (2003), Freedom from Command and Control: A Better Way to Make the Work Work, Buckingham: Vanguard Education.

Srivastava, M. (2011), “Anxiety, Stress and Satisfaction among Professionals in Manufacturing and Services Organisations: Fallout of Personal Values, Work Values and Extreme Job Conditions," Vision: The journal of business perspective, Vol.15 No.3, pp. 219-229.

Sluss, D. M., and Ashforth, B. E. (2007), "Relational Identity and Identification: Defining Ourselves through Work Relationships," Academy of Management Review, Vol.32 No.1, pp. 9 -32.

Sveningsson, S., and Alvesson, M. (2003), "Managing Managerial Identities: Organisational Fragmentation, Discourse and Identity Struggle," Evaluation, Vol.56 No.10, pp. 11631193.

Tripathy, M. (2002), "Burnout Stress Syndrome in Managers: A Study in A Manufacturing Industry," Management and Labour Studies, Vol.27 No.2, pp. 89-111.

Udo, G.J., Guimaraes, T., and Igbaria, M. (1997), “An Investigation of the Antecedents of Turnover Intention for Manufacturing Plant Managers," International Journal of Operations and Production Management, Vol.17 No.9, pp. 912-930. 
Vidaillet, B., and C. Vignon. (2010), "Bringing Back the Subject into Management Education," Management Learning, Vol.41 No.2, pp. 221-41.

Walsh, K., and Gordon, J. R. (2008), “Creating an Individual Work Identity,” Human Resource Management Review, Vol.18 No.1, pp. 46-61

Warhurst, R. P. (2012), 'Leadership Development as Identity Formation: Middle managers' leadership learning from MBA study," Human Resource Development International, Vol.15 No.4, pp. 471-487.

Warhurst, R.P. (2011), “Managers' Practice and Managers' Learning as Identity Formation: Reassessing the MBA Contribution. Management Learning, Vol.42 No.3, pp. 261-278.

Watson, T. (2007), "Identity Work, Managing and Researching," in Exploring Identity: Concepts and Methods, Pullen, A., N. Beech, and D. Sims, eds. London: Palgrave, 13550 .

Wayne, J.H., Randel, A.E., and Stevens, J. (2006), "The Role of Identity and Work-Family Support in Work-Family Enrichment and its Work-Related Consequences," Journal of Vocational Behavior, Vol.69 No.3, pp. 445-461.

Yin, R., (2009), Case Study Research: Design and Methods, Thousand Oaks: Sage Publications. 